\title{
Epidermal growth factor receptor expression and gene copy number analysis in gastric carcinoma samples from Chinese patients
}

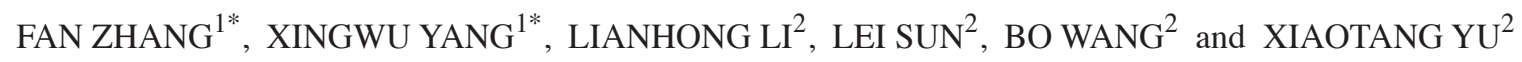 \\ ${ }^{1}$ Department of General Surgery, Second Affiliated Hospital of Dalian Medical University, Dalian, Liaoning 116027; \\ ${ }^{2}$ Department of Pathology and Forensic Medicine, Dalian Medical University, Dalian, Liaoning 116044, P.R. China
}

Received January 13, 2015; Accepted September 9, 2015

DOI: $10.3892 / \mathrm{ol} .2015 .3875$

\begin{abstract}
Epidermal growth factor receptor (EGFR) expression and gene copy number have been observed to be associated with a positive clinical response to EGFR inhibitors. The present study aimed to evaluate EGFR expression and gene copy number in samples of gastric carcinoma (GC) from Chinese patients. EGFR expression and gene copy number were detected using immunohistochemistry and fluorescence in situ hybridization, in tissue array slides containing 150 individual samples of GC tissue. The association between EGFR status, clinicopathological features and overall patient survival was analyzed. Out of the 150 cases of GC evaluated, $63(42.00 \%)$ demonstrated weak EGFR expression and $20(13.33 \%)$ demonstrated EGFR overexpression. EGFR expression was observed to be associated with tumor location $(\mathrm{P}<0.05)$. Out of 104 cases of $\mathrm{GC}$, which produced a clear FISH signal, 6 (5.77\%) exhibited EGFR gene amplification and $5(4.80 \%)$ exhibited balanced polysomy. Patients exhibiting GC, who demonstrated weak EGFR expression, EGFR overexpression or increased EGFR gene copy number, possessed an unfavorable prognosis. Multivariate analysis revealed that EGFR expression, tumor/node/metastasis stage and tumor location were potential independent unfavorable prognostic factors for GC patients. In conclusion, EGFR overexpression, gene amplification and polysomy were observed in GC patients and were associated with an unfavorable prognosis. Evaluation of EGFR status may therefore facilitate the identification of a subset of GC patients sensitive to treatment with EGFR-targeted therapies.
\end{abstract}

Correspondence to: Dr Xiaotang Yu, Department of Pathology and Forensic Medicine, Dalian Medical University, 9 Lushun South Road, Dalian, Liaoning 116044, P.R. China

E-mail: leahyxt@163.com

*Contributed equally

Key words: epidermal growth factor receptor, gene amplification, gastric carcinoma

\section{Introduction}

Gastric carcinoma (GC) is the second most common tumor worldwide (1). The highest mortality rates for GC have been reported in East Asia, including Japan, Korea and China (2). Currently, typical treatments for GC comprise surgery and chemotherapy, however recurrence frequently occurs, particularly with advanced stage GC (3). Currently, the majority of chemotherapy regimens are only able to achieve a low clinical complete response rate, and are not capable of improving overall survival rates (4). Therefore, the development of novel therapies for the treatment of GC is urgently required.

Epidermal growth factor receptor (EGFR/ErbB1) is a member of the ErbB family of receptor tyrosine kinases. The EGFR gene is located on the short arm of human chromosome 7 and produces a $170 \mathrm{kDa}$ transmembrane glycoprotein (5). When EGFR binds certain ligands, including epidermal growth factor or transforming growth factor- $\alpha$, it is capable of activating a number of intracellular signaling cascades, for example, the RAS/mitogen activated protein kinase, phosphatidylinositol-3-kinase and signal transducer and activator of transcription-3 signal transduction pathways $(6,7)$. These pathways regulate cell proliferation, migration, adhesion, differentiation and survival $(7,8)$.

Overexpression and/or increased activity of EGFR may be detected in a number of human tumors and is frequently associated with aggressive tumor behaviors and poor prognosis $(7,9)$. Therefore, EGFR is considered to be a significant therapeutic target for the treatment of human cancer. EGFR-targeting drugs have been developed and approved for use in the treatment of patients exhibiting EGFR-expressing non-small cell lung cancer (NSCLC) and colorectal carcinoma (CRC) $(9,10)$. Cetuximab and panitumumab are EGFR-binding monoclonal antibodies (mAbs), which are currently approved for use in the treatment of CRC (11). Gefitinib and erlotinib are EGFR tyrosine kinase inhibitors that are approved for use in the treatment of NSCLC (12).

In patients exhibiting advanced NSCLC, a positive response following treatment with tyrosine kinase inhibitor gefitinib was correlated with increased EGFR gene copy number and protein expression (13). Certain studies have identified overexpression of EGFR as a potential prognostic indicator for GC $(14,15)$. A 
small number of phase II and III clinical trials, in which GC was treated with cetuximab, have been performed, however ambiguous results were obtained $(16,17)$. It has been reported that the alteration of EGFR expression in GC may affect the sensitivity of EGFR-targeted therapies (18).

The incidence of EGFR overexpression and abnormalities in the EGFR gene may vary markedly across ethnicities (19). A small number of studies concerning EGFR status in Chinese GC patients have been published. The present study systemically evaluated EGFR protein expression and gene copy number in 150 samples of GC from Chinese patients. The associations between EGFR status, clinicopathological parameters and treatment outcomes were retrospectively analyzed. The present study may aid in the investigation of the viability of EGFR-targeting therapies as a potential treatment for GC in Chinese patients.

\section{Patients and methods}

Case selection and clinicopathological features. Patients pathologically diagnosed with gastric adenocarcinoma between April 2005 and June 2007 at the Second Affiliated Hospital of Dalian Medical University (Dalian, China) were selected for the current study. The current study was approved by the Institutional Review Board of Dalian Medical University. All participants signed a consent form prior to the commencement of surgical procedures and initiation of the study. Pathological specimens collected from the primary surgery were routinely fixed in formalin (Kan Nai Xin Zhongshan Biotechnology Co., Ltd., Zhongshan, China) and embedded in paraffin (Shanghai Hualing Health Machinery Plant, Shanghai, China). Each slide was re-evaluated by a pathologist, with no knowledge of the patient's pathological diagnosis, prior to the performance of experiments. Clinicopathological parameters were noted, including gender, age, tumor/node/metastasis (TNM) and pathological stages, depth of invasion, the presence of lymph node or distant metastasis and tumor location. Patient characteristics and details of each sample are listed in Table I.

Survival times were calculated from the initial surgery, and were considered censored for patients who were alive at the final follow-up or who succumbed with no evidence of GC recurrence. Clinical outcome was determined from the date of surgery until mortality, or 31 November 2013, which resulted in a follow-up period of 1-104 months (mean, 49 months). A total of $189 \mathrm{GC}$ cases were included at the initiation of the present study, however 39 cases were lost to follow-up. Patients (150 cases) who possessed complete prognosis data were included in the analysis.

Tissue array method. An expert pathologist evaluated the hematoxylin and eosin-stained (Sinopharm Chemical Reagent Co., Ltd., Shanghai, China) slides in order to ensure that the tissue-containing tumor cells were studied. Core tissue biopsy specimens (diameter, $2 \mathrm{~mm}$ ) were obtained from individual paraffin-embedded GC samples and arranged in recipient paraffin blocks. In order to account for tumor heterogeneity, two separate core samples per tumor were obtained. Non-neoplastic gastric mucosa specimens, which were obtained from adjacent normal tissue, were included in each of the array blocks; in total, 40 specimens were included.
The tissue array blocks contained up to 30 cores, meaning that 12 array blocks were formed from the 150 cases.

Immunohistochemistry (IHC) and interpretation of immunohistochemical results. Immunohistochemical staining of samples was performed using rabbit polyclonal $\operatorname{IgG}$ against EGFR (anti-EGFR; 1:50; sc03; Santa Cruz Biotechnology, Inc., Dallas, TX, USA) and avidin-biotin-peroxidase techniques (VECTASTAIN ${ }^{\circledR}$ Elite ABC kit; Vector Laboratories, Inc., Burlingame, CA, USA). Paraffin-embedded tissue sections $(4 \mu \mathrm{m})$ were deparaffinized and rehydrated. Endogenous peroxidase activity was ablated using $2 \% \mathrm{H}_{2} \mathrm{O}_{2}$-methanol (Tianjin Kermel Chemical Reagent Co., Ltd., Tianjin, China). Antigen retrieval was performed by microwave heating of slides in $10 \mathrm{mmol} / \mathrm{l}$ citrate buffer (Zhengzhou Cengfeng Chemical Products Co., Ltd., Zhengzhou, China) at pH 6.0, and 5\% normal sheep serum (Zhongshan Jinqiao Biotechnology Co., Inc., Beijing, China) was added to suppress nonspecific protein binding. Tissue sections were incubated at $37^{\circ} \mathrm{C}$ for $1 \mathrm{~h}$, and subsequently incubated at $4^{\circ} \mathrm{C}$ overnight with primary EGFR antibody. Certain tissue sections were incubated with 5\% serum in phosphate buffered saline (PBS; Zhongshan Jinqiao Biotechnology Co., Inc.) without antibody as a negative control. EGFR antibody was diluted 1:50 in 5\% serum. Sections were then washed with PBS and incubated with biotinylated goat anti-rabbit immunoglobulin G secondary antibody at $37^{\circ} \mathrm{C}$ for $1 \mathrm{~h}$. Following this initial incubation, cells were incubated a second time with avidin-biotin complex from the kit at $37^{\circ} \mathrm{C}$ for $45 \mathrm{~min}$. Color was developed using 3,3'-diaminobenzidine tetrahydrochloride (Zhongshan Jinqiao Biotechnology Co., Inc.). Slides were counterstained with hematoxylin.

Immunohistochemical staining for EGFR was evaluated using the following criteria: 0 , no discernible staining/background-type staining; $1+$, ambiguous discontinuous membrane staining; $2+$, moderate intensity membrane staining; and $3+$, strong and complete plasma membrane staining $(14,20)$. Immunohistochemical staining scores of $2+$ and $3+$ were considered to indicate EGFR overexpression.

Fluorescence in situ hybridization (FISH). Commercially available probes for the EGFR gene and centromere 7 (GLP EGFR/CSP 7 Dual Color Probe; Beijing Jinpujia Medical Technology Co., Ltd, Beijing, China) were utilized in the present study. Procedures were performed according to standard protocols (21). Briefly, 3-5 $\mu \mathrm{m}$ sectioned tissue array slides were deparaffinized, dehydrated, and incubated in $20 \%$ sodium bisulphate/2X standard saline citrate (2X SSC; Zhongshan Jinqiao Biotechnology Co., Inc.), at $75^{\circ} \mathrm{C}$ for $20 \mathrm{~min}$. Following washing in $2 \mathrm{X} \mathrm{SSC}$, slides were treated with proteinase K (Amresco LCC, Solon, OH, USA) at $37^{\circ} \mathrm{C}$ for $20 \mathrm{~min}$, rinsed in $2 \mathrm{X} \mathrm{SSC}$ at room temperature for $5 \mathrm{~min}$ and dehydrated using ethanol (Hongming Chemical Reagent Co.) in a series of increasing concentrations $(60,85,95$ and 100\%). EGFR and CEP7 probes were applied to each slide, covered with a glass coverslip and sealed using rubber cement (Citotest Labware Manufacturing Co., Ltd., Nanjing, China). Slides were denatured for $5 \mathrm{~min}$ at $83^{\circ} \mathrm{C}$ in a hybrite chamber (Citotest Labware Manufacturing Co., Ltd.) and hybridized overnight (for $\geq 8 \mathrm{~h}$ ) at $37^{\circ} \mathrm{C}$. Following post-hybridization 
Table I. Correlation of EGFR expression with clinicopathological parameters.

\begin{tabular}{|c|c|c|c|c|c|}
\hline \multirow[b]{2}{*}{ Clinicopathological parameter } & \multirow[b]{2}{*}{$\mathrm{n}$} & \multicolumn{3}{|c|}{ EGFR expression } & \multirow[b]{2}{*}{ P-value } \\
\hline & & - & $1+$ & $2+/ 3+$ & \\
\hline Gender & & & & & 0.315 \\
\hline Male & 122 & 56 & 48 & 18 & \\
\hline Female & 28 & 11 & 15 & 2 & \\
\hline Age, years & & & & & 0.113 \\
\hline$<65$ & 81 & 41 & 33 & 7 & \\
\hline$\geq 65$ & 69 & 26 & 30 & 13 & \\
\hline Diameter of tumor, $\mathrm{cm}$ & & & & & 0.786 \\
\hline$<5$ & 77 & 35 & 32 & 9 & \\
\hline$\geq 5$ & 73 & 31 & 31 & 11 & \\
\hline Tumor location & & & & & $0.013^{\mathrm{b}}$ \\
\hline Cardia and fundus & 17 & 2 & 10 & 5 & \\
\hline Body & 46 & 19 & 23 & 4 & \\
\hline Pylorus and antrum & 87 & 63 & 20 & 15 & \\
\hline Differentiation & & & & & 0.367 \\
\hline Well/moderate & 28 & 9 & 15 & 4 & \\
\hline Poor & 110 & 54 & 41 & 15 & \\
\hline Mucinous $^{\mathrm{a}}$ & 12 & 4 & 7 & 1 & \\
\hline Invasion depth & & & & & 0.301 \\
\hline Mucosa/submucosa & 12 & 4 & 7 & 1 & \\
\hline Muscular/serosa & 25 & 16 & 7 & 2 & \\
\hline Out of the serosa & 87 & 38 & 35 & 14 & \\
\hline Other organs & 26 & 9 & 14 & 3 & \\
\hline Lymph node metastases & & & & & 0.086 \\
\hline 0 & 43 & 14 & 21 & 8 & \\
\hline $1-6$ & 54 & 31 & 20 & 3 & \\
\hline$\geq 7$ & 53 & 22 & 22 & 9 & \\
\hline Distant metastases & & & & & 0.150 \\
\hline- & 127 & 61 & 50 & 16 & \\
\hline+ & 23 & 6 & 13 & 4 & \\
\hline Tumor/Node/Metastasis stage & & & & & 0.525 \\
\hline I & 22 & 9 & 10 & 3 & \\
\hline II & 31 & 13 & 14 & 4 & \\
\hline III & 67 & 36 & 23 & 8 & \\
\hline IV & 30 & 9 & 16 & 5 & \\
\hline
\end{tabular}

${ }^{a}$ Mucinous and signet ring cell carcinoma; ${ }^{b}$ statistically significant. EGFR, epidermal growth factor receptor.

washing, slides were counterstained using $10 \mu \mathrm{l}$ DAPI (Beyotime Biotechnology Co., Ltd., Shanghai, China) in antifade solution (Beijing Jinpujia Medical Technology Co., Ltd.), cover-slipped and examined under a fluorescence microscope (BX41; Olympus, Tokyo, Japan).

At least 60 tumor cell nuclei were counted per sample. Numbers of red (EGFR) and green (chromosome 7 centromere) signals were counted manually by Dr Xiaotang $\mathrm{Yu}$ and a technique assistant (Miss Li Wang of Beijing Jinpujia Medical Technology Co., Ltd.). For each FISH probe tested, the status of the chromosome was defined by the presence of the centromeric probe; CEP7 signals served as a control. The ratio of gene probe:centromeric probe was calculated. High levels of polysomy and gene amplification were regarded as a positive FISH result. Gene amplification was considered if tight EGFR gene clusters, a ratio of EGFR gene:chromosome of $\geq 2$ or $\geq 15$ copies of EGFR/cell in $\geq 10 \%$ of analyzed cells was observed. Polysomy was considered when $\geq 4$ copies of the EGFR gene were identified in $\geq 40 \%$ of cells, and was termed inconclusive if the EGFR:CEP7 signal ratio was observed to be $\geq 2$ in $\leq 10 \%$ of the analyzed cells $(15,22)$.

Statistical analysis. Statistical analysis was performed using SPSS version 19.0 (IBM SPSS, Armonk, NY, USA). Associations 
A

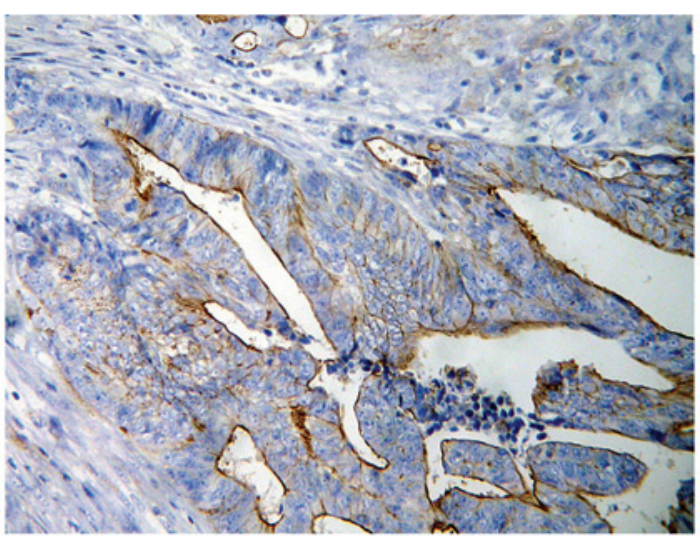

B

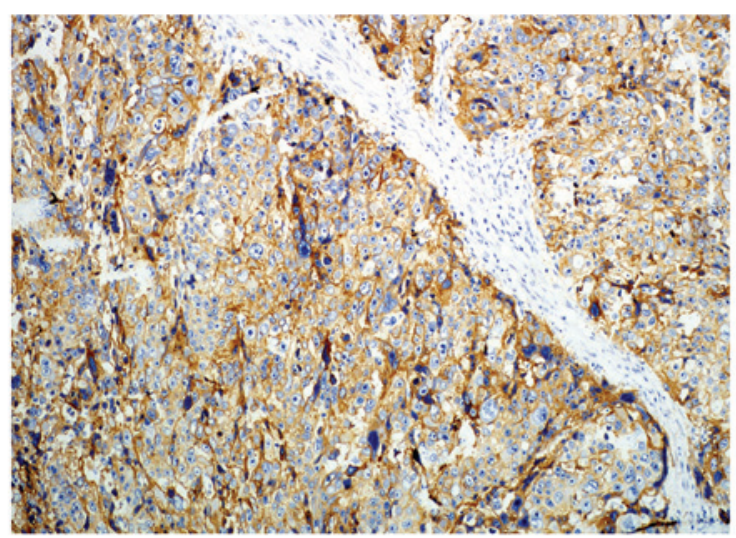

Figure 1. Immunohistochemical analysis of EGFR protein expression in GC. (A) GC exhibiting weak EGFR expression. (B) GC exhibiting EGFR overexpression (magnification, x200). EGFR, epidermal growth factor receptor; GC, gastric carcinoma.

A

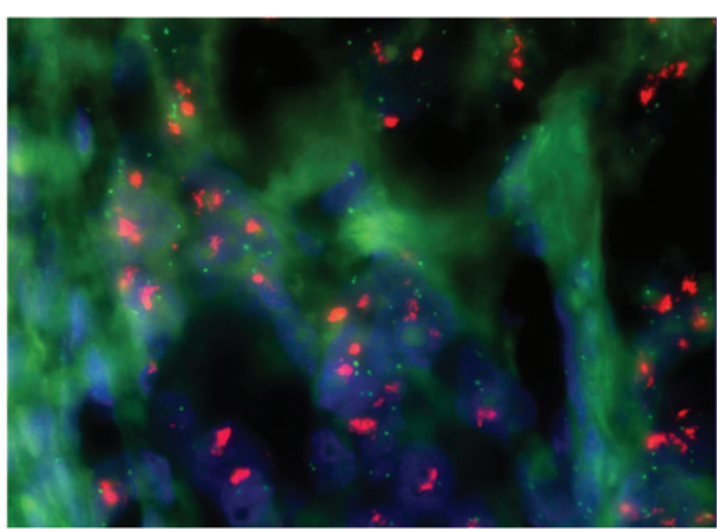

B

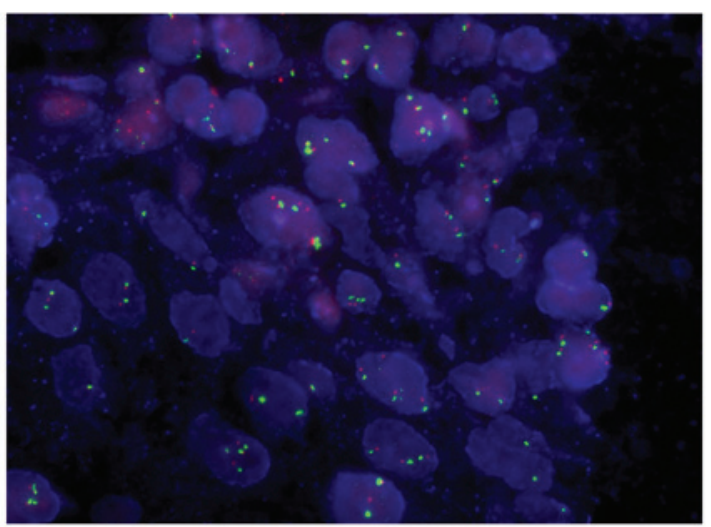

Figure 2. Fluorescence in situ hybridization analysis of EGFR gene copy number in GC. EGFR produced a red signal and chromosome 7 centromere produced a green signal; nuclei were stained by DAPI which appeared as a blue signal. (A) GC cells exhibiting gene amplification demonstrated a formation of clusters with numerous signals for EGFR. (B) GC cells exhibiting increased EGFR copy number due to chromosome 7 polysomy (magnification, x100). EGFR, epidermal growth factor receptor; GC, gastric carcinoma.

between EGFR expression and clinicopathological characteristics were assessed by Kruskal-Wallis and Mann-Whitney $\mathrm{U}$ test analysis. Groups were compared using the Pearson $\chi^{2}$ test. Survival curves were constructed using Kaplan-Meier analysis, and the significance of differences between survival curves was determined using the log-rank test. Multivariate analysis was performed using Cox proportional hazards regression. All statistical tests were two-sided. $\mathrm{P}<0.05$ was considered to indicate a statistically significant difference.

\section{Results}

High EGFR expression is correlated with the presence of $G C$ at the cardia and fundus. EGFR protein expression was determined using IHC in tissue array slides containing 150 samples of GC (Fig. 1). EGFR staining in GC was detected in the membrane and/or cytoplasm. Out of a total of 150 samples, 67 cases (44.67\%) scored 0, $63(42.00 \%)$ scored $1+$ and $20(13.33 \%)$ scored $2+$ or $3+$. A score of $1+$ was considered to demonstrate weak EGFR expression, while a score of $2+$ or $3+$ was considered to demonstrate EGFR overexpression. Associations between EGFR protein expression and clinicopathological parameters were analyzed and are summarized in Table I. The results of the present study revealed that EGFR is highly expressed in GC located at the cardia and fundus $(\mathrm{P}=0.012)$. There were no significant correlations observed between EGFR protein expression and any other clinicopathological features $(\mathrm{P}>0.05)$.

Increased EGFR gene amplification is correlated with high levels of EGFR protein expression. EGFR gene amplification was detected using FISH in tissue array slides containing $150 \mathrm{GC}$ samples. In a total of 150 cases of GC, 46 failed to produce a clear signal for evaluation, while 104 cases exhibited a clear signal that was able to be used for enumerating analysis. EGFR protein expression in these 104 cases of GC was as follows: 41 cases scored 0,45 cases scored $1+$ and 18 scored 2+ or 3+. All EGFR signals were compared with signals for centromeric probes for chromosome 7. EGFR amplification was detected in $5.77 \%(6 / 104)$ of the cases, which exhibited red cluster signals for EGFR (Fig. 2A). Four cases demonstrated EGFR protein overexpression $(2+/ 3+)$ and two cases exhibited weak EGFR expression (1+). An increased gene copy number due to polysomy was detected in $4.81 \%(5 / 104)$ of the cases (Fig. 2B); three of these cases demonstrated EGFR protein overexpression and two 
Table II. Univariate analysis of EGFR status, clinicopathological parameters and overall cancer survival in subjects with gastric carcinoma.

\begin{tabular}{|c|c|c|c|c|}
\hline \multirow[b]{2}{*}{ Clinicopathological parameter } & \multirow[b]{2}{*}{$\mathrm{n}$} & \multirow{2}{*}{$\begin{array}{c}\text { Mean overall } \\
\text { survival, months }\end{array}$} & \multicolumn{2}{|c|}{ Overall survival } \\
\hline & & & $95 \% \mathrm{CI}$ & P-value \\
\hline Gender & & & & 0.747 \\
\hline Male & 122 & 52.643 & $37.978-67.308$ & \\
\hline Female & 28 & 54.869 & $47.441-62.297$ & \\
\hline Age, years & & & & 0.169 \\
\hline$<65$ & 81 & 58.508 & 49.011-68.001 & \\
\hline$\geq 65$ & 69 & 50.886 & $41.558-60.213$ & \\
\hline Diameter, cm & & & & $0.005^{\mathrm{b}}$ \\
\hline$<5$ & 77 & 64.602 & $55.414-73.786$ & \\
\hline$\geq 5$ & 73 & 44.562 & $35.338-53.785$ & \\
\hline Tumor location & & & & $0.022^{\mathrm{b}}$ \\
\hline Cardia and fundus & 17 & 31.882 & $16.042-47.693$ & \\
\hline Body & 46 & 56.043 & $44.558-67.652$ & \\
\hline Pylorus and antrum & 87 & 58.437 & $49.453-67.420$ & \\
\hline Differentiation & & & & 0.682 \\
\hline Well/moderate & 28 & 56.357 & $41.111-71.604$ & \\
\hline Poor & 110 & 55.138 & $47.481-62.795$ & \\
\hline Mucinous $^{\mathrm{a}}$ & 12 & 43.583 & $18.995-68.172$ & \\
\hline Invasion depth & & & & $<0.000^{\mathrm{b}}$ \\
\hline Mucosa/submucosa & 12 & 80.583 & $65.241-95.925$ & \\
\hline Muscular/serosa & 25 & 84.880 & $71.800-97.960$ & \\
\hline Out of the serosa & 87 & 52.243 & $43.781-60.704$ & \\
\hline Other organs & 26 & 19.385 & $10.732-28.037$ & \\
\hline Lymph node metastases & & & & $<0.000^{\mathrm{b}}$ \\
\hline 0 & 43 & 72.519 & $60.360-84.679$ & \\
\hline $1-6$ & 54 & 57.630 & $47.716-67.543$ & \\
\hline$\geq 7$ & 53 & 35.679 & $25.672-45.687$ & \\
\hline Distant metastases & & & & $<0.000^{\mathrm{b}}$ \\
\hline- & 127 & 61.643 & $54.455-68.830$ & \\
\hline+ & 23 & 18.000 & $9.222-26.778$ & \\
\hline Tumor/Node/Metastasis stage & & & & $<0.000^{\mathrm{b}}$ \\
\hline I & 22 & 94.000 & 84.029-103.971 & \\
\hline II & 31 & 64.323 & $50.520-78.117$ & \\
\hline III & 67 & 53.836 & $44.441-63.261$ & \\
\hline IV & 30 & 16.567 & $9.463-23.671$ & \\
\hline EGFR & & & & $0.011^{\mathrm{b}}$ \\
\hline- & 67 & 66.635 & $56.692-76.578$ & \\
\hline $1+$ & 63 & 46.507 & $37.066-55.949$ & \\
\hline $2+/ 3+$ & 20 & 41.650 & 24.353-58.947 & \\
\hline EGFR gene amplification and polysomy & & & & $0.040^{\mathrm{b}}$ \\
\hline- & 93 & 54.222 & $45.419-63.024$ & \\
\hline+ & 11 & 32.182 & $13.421-50.942$ & \\
\hline
\end{tabular}

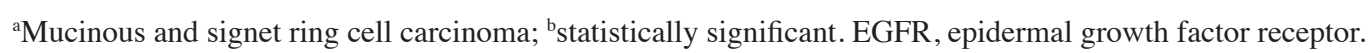

exhibited weak expression. The other 93 cases that produced clear signals for analysis possessed balanced EGFR and
CEP7 copy numbers. In the EGFR overexpression and EGFR weak expression groups, the frequencies of gene copy 
Table III. Multivariate analysis of predictive indicators for survival of patients exhibiting gastric carcinoma.

\begin{tabular}{|c|c|c|c|c|c|c|}
\hline Clinicopathological parameter & $\mathrm{B}$ & Standard error & Wald $^{\mathrm{a}}$ & Mean RR & $95 \% \mathrm{CI}$ of RR & P-value \\
\hline Gender & 0.403 & 0.288 & 1.961 & 1.497 & $0.851-2.632$ & 0.161 \\
\hline Age & 0.191 & 0.224 & 0.730 & 1.211 & $0.781-1.878$ & 0.393 \\
\hline Diameter & -0.156 & 0.235 & 0.441 & 0.855 & $0.539-1.357$ & 0.507 \\
\hline Site & -0.442 & 0.168 & 6.930 & 0.643 & $0.462-0.893$ & $0.008^{\mathrm{b}}$ \\
\hline Differentiation & 0.102 & 0.243 & 0.178 & 1.108 & $0.689-1.782$ & 0.673 \\
\hline Invasive depth & 0.341 & 0.239 & 2.033 & 1.407 & $0.880-2.248$ & 0.154 \\
\hline TNM stage & 0.806 & 0.202 & 16.005 & 2.240 & $1.509-3.325$ & $0.000^{\mathrm{b}}$ \\
\hline EGFR expression & 0.387 & 0.150 & 6.640 & 1.473 & $1.097-1.976$ & $0.010^{\mathrm{b}}$ \\
\hline
\end{tabular}

${ }^{a}$ Wald statistic was calculated using the following equation: Wald $=(\mathrm{B} / \text { standard error })^{2}$; ${ }^{\mathrm{b}}$ Statistically significant. B, partial correlation coefficient; RR, relative risk; CI, confidence interval; EGFR, epidermal growth factor receptor; TNM, tumor/node/metastasis; EGFR, epidermal growth factor receptor.
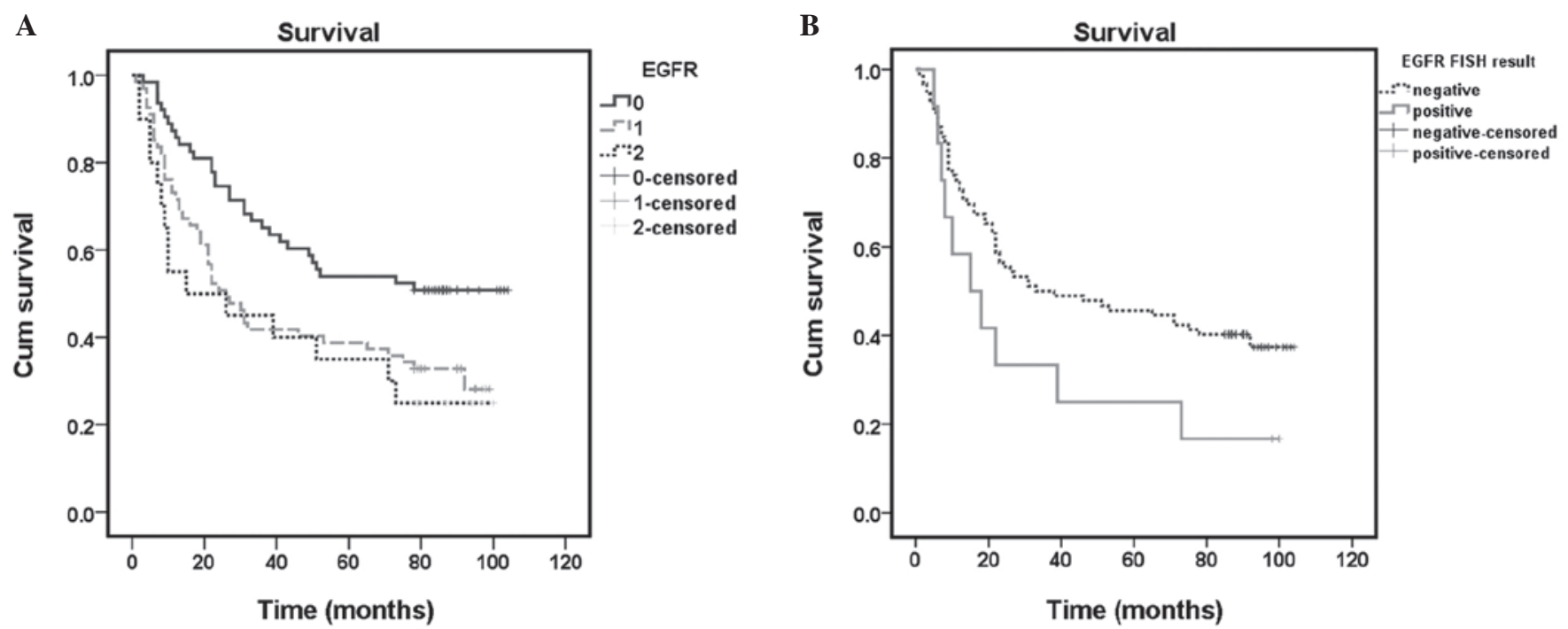

Figure 3. Survival curves constructed using the Kaplan-Meier method and log-rank test. (A) Survival curves revealed that GC patients exhibiting weak EGFR expression (1+) and EGFR overexpression (2+) possessed an unfavorable prognosis compared with EGFR-negative GC patients (0). (B) Survival curves revealed that GC patients demonstrating increased EGFR gene copy numbers, as detected by FISH, possessed an unfavorable prognosis. GC, gastric carcinoma; EGFR, epidermal growth factor receptor; FISH, fluorescence in situ hybridization; Cum, cumulative.

number abnormalities were $38.89(7 / 18)$ and $8.89 \%(4 / 45)$ respectively. None of the 41 cases demonstrating negative EGFR expression exhibited EGFR gene amplification or high polysomy. Mann-Whitney U test analysis revealed that the correlation between IHC and FISH results was statistically significant $(\mathrm{P}<0.001)$. It was concluded that increased copy number of the EGFR gene was associated with GC cases with high EGFR protein expression levels.

Survival analysis. The duration of follow-up was 1-104 months (mean, 48.9 months) subsequent to surgery; $92 / 150$ patients $(61.33 \%)$ succumbed during this period. Univariate analysis revealed that tumor diameter, site, depth of invasion, presence of lymph node or distant metastases, TNM stage, EGFR expression and EGFR gene amplification were associated with prognosis (Table II). Additional factors, including gender, age and differentiation of $\mathrm{GC}$, were not associated with prognosis $(\mathrm{P}>0.05)$. The overall survival rate of patients exhibiting negative EGFR expression, as determined using the log-rank test, was significantly increased compared with the survival rate of those patients demonstrating EGFR expression ( $\mathrm{P}=0.001$; Fig. 3A). However, there was no significant difference in survival rate between patients exhibiting weak EGFR expression and EGFR overexpression. Patients exhibiting EGFR FISH(+) GC possessed a less favorable prognosis compared with those exhibiting EGFR FISH(-) GC (P=0.036; Fig. 3B).

Clinicopathological parameters, including gender, age, tumor diameter, location and differentiation, TNM stage and EGFR expression were included in a multivariate analysis. The results of this analysis revealed that EGFR expression, tumor location and TNM stage were independent prognostic indicators of GC (Table III). However, there were no significant differences between subjects exhibiting EGFR FISH(+) GC and those demonstrating EGFR FISH(-) GC ( $\mathrm{P}=0.682)$ detected in the multivariate analysis. 


\section{Discussion}

EGFR inhibitors are utilized in the management of a number of solid malignant tumors, including CRC and metastatic NSCLC $(23,24)$. Due to the development of EGFR-targeted treatments, the EGFR gene has been identified in a variety of studies investigating numerous malignancies $(25,26)$. In the present study, EGFR protein expression and gene amplification were systemically evaluated in GC samples from Chinese patients.

IHC is the typical tool for the determination of EGFR expression levels and for the identification of patients likely to benefit from EGFR-targeted therapies in CRC and NSCLC (27). In GC, EGFR protein expression has been analyzed in several previous studies. Kim et al (15) evaluated EGFR status in 511 Korean GC cases; $27.4 \%$ of these cases demonstrated EGFR overexpression. Takehana et al (28) identified negative EGFR protein expression in $89.6 \%$, low levels in $8.2 \%$ and high levels of expression in $2.2 \%$ of $413 \mathrm{GC}$ specimens from Japanese patients. Gamboa-Dominguez et al (14) investigated EGFR status in 87 cases of GC from Mexican patients; $18.0 \%$ demonstrated moderate EGFR expression and $10.1 \%$ exhibited strong EGFR expression. The results of the present study revealed that EGFR expression was observed in 83/150 (55.33\%) GC cases, and $20(13.33 \%)$ cases demonstrated EGFR overexpression. In the present and previous studies, the frequency of EGFR overexpression, as revealed by IHC, ranged between $2-30 \%$. Potential reasons for this wide variation may include differences in fixation techniques, antibodies and scoring systems used in IHC (29).

EGFR overexpression may occur as a result of the presence of an increased gene copy number. The present study investigated EGFR gene copy number using FISH analysis in tissue array slides. A total of 104 cases of GC exhibited a positive signal; while the remaining 46 cases failed to produce any signal. This low rate of success in the FISH analysis may be a result of the extended storage time of samples, as well as the tissue array slides used in FISH analysis. A number of the wax tissue blocks had been stored for $>10$ years prior to being utilized for the present study. A longer storage time may lead to fewer positive results, as the following factors may exhibit a considerable impact on the preservation of DNA/mRNA: Oxidation, hydrolysis, sun or light exposure, fixation time and type of fixative (30). This problem may be resolved by punching multiple small cores from different regions to capture the heterogeneity of the tumors more effectively. In addition, the detection of oncogene amplification by fluorescent in situ hybridization on tissue microarray may be a reliable tool for large retrospective studies. Various tissues arranged in one tissue array slide may require alternative experimental conditions to achieve a positive result (31). Furthermore, due to the heterogeneity of various areas of GC tumors, the rate of increased gene copy number that was detected in the tissue array slides may be lower than indicated according to the results of the present study.

In these 104 cases of GC, EGFR gene amplification was detected in six cases and polysomy in five. A number of EGFR overexpression cases $(7 / 18 ; 38.89 \%)$ demonstrated
EGFR gene amplification or high polysomy as revealed by FISH, whereas these features were observed in only $4 / 45$ cases (8.89\%) exhibiting weak EGFR expression. The present study confirmed that EGFR IHC scores were significantly correlated with EGFR gene expression levels. This observation also suggested that not all GC cases exhibiting increased EGFR gene copy number demonstrated EGFR protein overexpression; and that a number of cases exhibited weak expression. Therefore, if patients possessing increased EGFR gene copy number are sensitive to EGFR-targeted drugs, certain patients demonstrating weak EGFR expression may also potentially benefit from treatment with these drugs. Univariate analysis revealed that EGFR overexpression and gene copy number were associated with unfavorable prognoses. Multivariate analysis revealed that EGFR expression was an independent prognostic indicator. The potential value of the results of the present study is that they may facilitate the identification of a subset of patients exhibiting tumors that may be sensitive to EGFR-targeted therapy. Patients exhibiting EGFR overexpression possess a poor prognosis, however these patients may benefit from EGFR-targeted therapy.

The EGFR gene status of GC has been analyzed in previous studies. Kim et al (15) evaluated the EGFR gene copy number in GC tissues from 511 Korean patients; 13/21 (61.9\%) cases demonstrating EGFR overexpression also exhibited EGFR gene amplification or increased polysomy, while only 14/119 (11.8\%) cases possessing weak EGFR expression exhibited EGFR gene amplification or high polysomy. Liang et al (20) detected the EGFR gene copy number in 100 cases of GC; $16 \%$ of these GC specimens demonstrated positive FISH results (20). These results were consistent with those of the present study. The frequency of increased EGFR gene copy number in GC is reduced compared with certain other malignancies, including NSCLC, CRC and high-grade gliomas $(13,32,33)$.

Clinical trials have been undertaken to investigate the effect of EGFR-targeting mAbs in GC. In a multicenter phase II Japanese study, 13/75 metastatic GC patients receiving gefitinib treatment achieved disease control (34). By contrast, a phase II trial of erlotinib conducted in two groups of patients with gastroesophageal junction (GEJ) or cardia and distal gastric adenocarcinomas demonstrated that erlotinib is an effective treatment for patients with GEJ adenocarcinomas, however, it appears ineffective for the treatment of distal GC (35). An additional phase III clinical trial (EXPAND) revealed a small subset of patients that responded to treatment with cetuximab (16). The results of these previous studies emphasize the requirement for the identification of latent responders.

In NSCLC and CRC, patients exhibiting EGFR overexpression and/or an increased gene copy number have been demonstrated to possess a positive response to EGFR-targeted therapies for carcinoma $(29,32,36)$. A number of previous in vitro studies have suggested that GC patients exhibiting EGFR overexpression or gene amplification may benefit from EGFR-targeted therapy. Fukuda et al (37) identified that the combination of 5-fluorouracil and cetuximab synergistically inhibited cell proliferation and exhibited an enhanced pro-apoptotic effect in GC cells demonstrating 
EGFR overexpression. A preclinical trial identified that GC patient-derived xenografts responded to cetuximab, and efficacy was dependent on EGFR overexpression and gene amplification (17). IHC analysis of EGFR expression, including FISH analysis of the EGFR gene, may be a favorable option for the identification of latent patients, who may respond to EGFR-targeted therapies.

In conclusion, the results of the present study provide evidence that EGFR expression may be significantly associated with an unfavorable prognosis in GC. The present study additionally identified that gene amplification and polysomy were low frequency events in GC, although were associated with poor prognosis. An increased copy number of the EGFR gene was significantly correlated with protein overexpression. The results of the present study therefore suggest that there is a potential group of GC patients that may benefit from treatment with EGFR-targeted agents.

\section{Acknowledgements}

This present study was supported by the Department of Education, Liaoning Province (grant no. L2011157).

\section{References}

1. Amedei A, Benagiano M, della Bella C, Niccolai E and D'Elios MM: Novel immunotherapeutic strategies of gastric cancer treatment. J Biomed Biotechnol 2011: 437348, 2011.

2. Ferlay J, Shin HR, Bray F, Forman D, Mathers C and Parkin DM: Estimates of worldwide burden of cancer in 2008: GLOBOCAN 2008. Int J Cancer 127: 2893-2917, 2010.

3. De Vita F, Di Martino N, Fabozzi A, Laterza MM, Ventriglia J, Savastano B, Petrillo A, Gambardella V, Sforza $\mathrm{V}$, Maranwo L, et al: Clinical management of advanced gastric cancer: the role of new molecular drugs. World J Gastroenterol 20: 14537-14558, 2014

4. Roviello F, Caruso S, Neri A and Marrelli D: Treatment and prevention of peritoneal carcinomatosis from gastric cancer by cytoreductive surgery and hyperthermic intraperitoneal chemotherapy: Overview and rationale. Eur J Surg Oncol 39: 1309-1316, 2013

5. Yk W, Cf G, T Y, Z C, Xw Z, Xx L, Nl M and Wz Z: Assessment of ERBB2 and EGFR gene amplification and protein expression in gastric carcinoma by immunohistochemistry and fluorescence in situ hybridization. Mol Cytogenet 4: 14, 2011.

6. Ghosh MK, Sharma P, Harbor PC, Rahaman SO and Haque SJ: PI3K-AKT pathway negatively controls EGFR-dependent DNA-binding activity of Stat 3 in glioblastoma multiforme cells. Oncogene 24: 7290-7300, 2005.

7. Yu XT, Zhu SN, Xu ZD, Hu XQ, Zhu TF, Chen JQ and Lu SL: Roles of EGFR-Stat 3 signal pathway in carcinogenesis of experimental hepatoma in rats. J Cancer Res Clin Oncol 133: 145-152, 2007.

8. Mok TS, Lee K and Leung L: Targeting epidermal growth factor receptor in the management of lung cancer. Semin Oncol 41: 101-109, 2014.

9. Ruzzo A, Graziano F, Canestrari E and Magnani M: Molecular predictors of efficacy to anti-EGFR agents in colorectal cancer patients. Curr Cancer Drug Targets 10: 68-79, 2010.

10. Liang JL, Ren XC and Lin Q: Treating advanced non-small-cell lung cancer in Chinese patients: Focus on icotinib. Onco Targets Ther 7: 761-770, 2014

11. Diasio RB and Fourie J: Targeting the epidermal growth factor receptor in the treatment of colorectal cancer: State of the art Drugs 66: 1441-1463, 2006.

12. Lynch TJ, Bell DW, Sordella R, Gurubhagavatula S, Okimoto RA, Brannigan BW, Harris PL, Haserlat SM, Supko JG, Haluska FG, et al: Activating mutations in the epidermal growth factor receptor underlying responsiveness of non-small-cell lung cancer to gefitinib. N Engl J Med 350: 2129-2139, 2004.
13. Cappuzzo F, Hirsch FR, Rossi E, Bartolini S, Ceresoli GL, Bemis L, Haney J, Witta S, Danenberg K, Domenichini I, et $a l$ : Epidermal growth factor receptor gene and protein and gefitinib sensitivity in non-small-cell lung cancer. J Natl Cancer Inst 97: 643-655, 2005.

14. Gamboa-Dominguez A, Dominguez-Fonseca C, Quintanilla-Martinez L, Reyes-Gutierrez E, Green D, Angeles-Angeles A, Busch R, Hermannstädter C, Nährig J, et al: Epidermal growth factor receptor expression correlates with poor survival in gastric adenocarcinoma from Mexican patients: A multivariate analysis using a standardized immunohistochemical detection system. Mod Pathol 17: 579-587, 2004.

15. Kim MA, Lee HS, Lee HE, Jeon YK, Yang HK and Kim WH: EGFR in gastric carcinomas: Prognostic significance of protein overexpression and high gene copy number. Histopathology 52 : 738-746, 2008.

16. Lordick F, Kang YK, Chung HC, Salman P, Oh SC, Bodoky G, Kurteva G, Volovat C, Moiseyenko VM, Gorbunova V, et al; Arbeitsgemeinschaft Internistische Onkologie and EXPAND Investigators: Capecitabine and cisplatin with or without cetuximab for patients with previously untreated advanced gastric cancer (EXPAND): A randomised, open-label phase 3 trial. Lancet Oncol 14: 490-499, 2013.

17. Zhang L, Yang J, Cai J, Song X, Deng J, Huang X, Chen D, Yang M, Wery JP, Li S, et al: A subset of gastric cancers with EGFR amplification and overexpression respond to cetuximab therapy. Sci Rep 3: 2992, 2013.

18. Kim JG: Molecular targeted therapy for advanced gastric cancer. Korean J Intern Med 28: 149-155, 2013.

19. Metzger B, Chambeau L, Begon DY, Faber C, Kayser J, Berchem G, Pauly M, Boniver J, Delvenne P, Dicato M and Wenner t: The human epidermal growth factor receptor (EGFR) gene in European patients with advanced colorectal cancer harbors infrequent mutations in its tyrosine kinase domain. BMC Med Genet 12: 144 2011.

20. Liang Z, Zeng X, Gao J, Wu S, Wang P, Shi X, Zhang J and Liu T: Analysis of EGFR, HER2, and TOP2A gene status and chromosomal polysomy in gastric adenocarcinoma from Chinese patients. BMC Cancer 8: 363, 2008.

21. Wang Y, Jiang CQ, Guan J, Yang GF, Yue JQ, Chen HL, Xue JL, Xu ZG, Qian Q and Fan LF: Molecular alterations of EGFR in small intestinal adenocarcinoma. Int J Colorectal Dis 28: 1329-1335, 2013.

22. Ciardiello F and Tortora G: Epidermal growth factor receptor (EGFR) as a target in cancer therapy: Understanding the role of receptor expression and other molecular determinants that could influence the response to anti-EGFR drugs. Eur J Cancer 39: 1348-1354, 2003.

23. Castañón E, Martín P, Rolfo C, Fusco JP, Ceniceros L, Legaspi J, Santisteban M and Gil-Bazo I: Epidermal Growth Factor Receptor targeting in non-small cell lung cancer: revisiting different strategies against the same target. Curr Drug Targets 15: 1273-1283, 2014.

24. Yarom N and Jonker DJ: The role of the epidermal growth factor receptor in the mechanism and treatment of colorectal cancer. Discov Med 11: 95-105, 2011.

25. Lozano MD, Zulueta JJ, Echeveste JI, Gúrpide A, Seijo LM, Martín-Algarra S, Del Barrio A, Pio R, Idoate MA, Labiano T and Perez-Gracia JL: Assessment of epidermal growth factor receptor and K-ras mutation status in cytological stained smears of non-small cell lung cancer patients: Correlation with clinical outcomes. Oncologist 16: 877-885, 2011.

26. Scartozzi M, Bearzi I, Mandolesi A, Pierantoni C, Loupakis F, Zaniboni A, Negri F, Quadri A, Zorzi F, Galizia E, et al: Epidermal Growth Factor Receptor (EGFR) gene copy number (GCN) correlates with clinical activity of irinotecan-cetuximab in K-RAS wild-type colorectal cancer: a fluorescence in situ (FISH) and chromogenic in situ hybridization (CISH) analysis. BMC Cancer 9: 303.

27. Takehana T, Kunitomo K, Suzuki S, Kono K, Fujii H, Matsumoto Y and Ooi A: Expression of epidermal growth factor receptor in gastric carcinomas. Clin Gastroenterol Hepatol 1: 438-445, 2003.

28. Terashima M, Kitada K, Ochiai A, Ichikawa W, Kurahashi I, Sakuramoto S, Katai H, Sano T, Imamura H and Sasako M; ACTS-GC Group: Impact of expression of human epidermal growth factor receptors EGFR and ERBB2 on survival in stage II/III gastric cancer. Clin Cancer Res 18: 5992-6000, 2012.

29. Cappuzzo F, Finocchiaro G, Rossi E, Jänne PA, Carnaghi C, Calandri C, Bencardino K, Ligorio C, Ciardiello F, Pressiani T, et al: EGFR FISH assay predicts for response to cetuximab in chemotherapy refractory colorectal cancer patients. Ann Oncol 19: 717-723, 2008. 
30. Economou M, Schöni L, Hammer C, Galván JA, Mueller DE and Zlobec I: Proper paraffin slide storage is crucial for translational research projects involving immunohistochemistry stains. Clin Transl Med 3: 4, 2014.

31. Brown LA and Huntsman D: Fluorescent in situ hybridization on tissue microarrays: challenges and solutions. J Mol Histol 38:151-157, 2007.

32. Viana-Pereira M, Lopes JM, Little S, Milanezi F, Basto D, Pardal F, Jones C and Reis RM: Analysis of EGFR overexpression, EGFR gene amplification and the EGFRvIII mutation in Portuguese high-grade gliomas. Anticancer Res 28: 913-920, 2008.

33. Rojo F, Tabernero J, Albanell J, Van Cutsem E, Ohtsu A, Doi T, Koizumi W, Shirao K, Takiuchi H, Ramon y Cajal $\mathrm{S}$ and Baselga $\mathrm{J}$ : Pharmacodynamic studies of gefitinib in tumor biopsy specimens from patients with advanced gastric carcinoma. J Clin Oncol 24: 4309-4316, 2006.
34. Dragovich T, McCoy S, Fenoglio-Preiser CM, Wang J, Benedetti JK, Baker AF, Hackett CB, Urba SG, Zaner KS, Blanke CD and Abbruzzese JL: Phase II trial of erlotinib in gastroesophageal junction and gastric adenocarcinomas: SWOG 0127. J Clin Oncol 24: 4922-4927, 2006.

35. Gancberg D, Di Leo A, Rouas G, Järvinen T, Verhest A, Isola J, Piccart MJ and Larsimont D: Reliability of the tissue microarray based FISH for evaluation of the HER-2 oncogene in breast carcinoma. J Clin Pathol 55: 315-317, 2002.

36. Lièvre A, Bachet JB, Le Corre D, Boige V, Landi B, Emile JF, Côté JF, Tomasic G, Penna C, Ducreux M, et al: KRAS mutation status is predictive of response to cetuximab therapy in colorectal cancer. Cancer Res 66: 3992-3995, 2006.

37. Fukuda K, Saikawa Y, Takahashi M, Takahashi T, Wada N, Kawakubo H, Takeuchi H and Kitagawa Y: Antitumor effect of cetuximab in combination with S-1 in EGFR-amplified gastric cancer cells. Int J Oncol 40: 975-982, 2012. 